\title{
Biomass Extract of Ipomea carnea and Its Inhibition against Trichoderma asperellum
}

\author{
Sutarman ${ }^{*}, A$. Miftahurrohmat, $A E$. Prihatiningrum, $S$. Arifin \\ Department of Agrotechnology, Faculty of Science and Technology, Universitas Muhammadiyah \\ Sidoarjo, Indonesia
}

\begin{abstract}
This study aims to determine the type of metabolites contained in the extraction of Ipomea carnea canopy biomass and its inhibitory effect in vitro against Trichoderma asperellum Tc-Jjr-02 which has been tested as an active ingredient in bio fungicides and biofertilizers. The initial stage of the research is the determination of the metabolites contained in the extract with methanol solvent through Gas Chromatography-Mass Spectrophotometry (GCMS) analysis. The next step was an in vitro test of the extract's inhibitory power to the growth of $T$. asperellum fungal colonies during the incubation period of up to 96 hours. The results of GCMS analysis of extracts with methanol solvents obtained 24 types of metabolites, some of which can inhibit fungal growth. Crude extract of canopy biomass of $I$. carnea at a concentration of $2 \%$ inhibited the growth of all Trichoderma isolates by $20.97 \pm 3.36 \%$ (Tc-Jjr-02 ), $38.15 \pm 32.59 \%$ (Tc-Sba-01), and $45.30 \pm 1.86 \%$ (Tc-Jro-01), while at a concentration of $20 \%$ inhibited isolates Tc-Sba- 01 and Tc- Jro- 01 were $35.19 \pm 4.90 \%$ and $42.59 \pm 1.85 \%$ in vitro at 96 hours after inoculation, respectively. The isolate of T. esperellum Tc-Jjr-02 has the potential to be formulated with $I$. carnea biomass as compost in the future.
\end{abstract}

\section{Introduction}

Each country develops a national scenario to reduce $\mathrm{CO}_{2}$ emissions according to the Paris Agreement [1], including in the agricultural sector. The use of synthetic chemical fertilizers and pesticides should be further reduced and even avoided. The facts show that the application of synthetic chemical pesticides results in the suppression of non-target organisms [2], the resistance of nuisance organisms [3], environmental pollution [4], and threatens human health [5]. For this reason, efforts to find and use environmentally friendly alternative materials in agricultural cultivation must continue to be improved.

Research and application of Trichoderma fungi have been developed to increase plant resistance and protect plants from attack by harmful pathogens. As the characteristics of the role that have been determined by researchers from various countries in the world, several Trichoderma isolates isolated from agricultural land and plantation forest lands in East Java (Indonesia) have also been tested for their ability to increase growth and plant protection to suppress damping-off soybeans [6], Fusarium wilt and anthracnose of chili plants [7-8], as

\footnotetext{
* Corresponding author: sutarman@umsida.ac.id
} 
well as being able to control potato leaf blight pathogens [9], and bacterial wilt of tobacco plants [10]. Its potential as a biopesticide that is applied by smearing the stems of citrus plants provides prospects for application to various other agricultural crops.

The utilization of Trichoderma as a biological agent for easy handling requires a carrier material, including by using easily available plant biomass. Meanwhile, plant biomass, including crop residues from agricultural waste, is widely used in fertilizing as compost which aims to increase the availability of nutrients for plants. Besides that, the compost also has great potential as a carrier agent and inert biological agent, both as biological fertilizer and/or biopesticide, so that it can be used as a biofertilizer.

I. carnea contains various pharmaceutical chemical compounds [11], proven to also be used as compost, and can even be used as a biopesticide capable of controlling insect pests [12] and controlling fungal pathogens [13] because it contains various fungistatic compounds.

For efficiency purposes in the application, there is potential to combine I. carnea biomass as compost as well as a carrier agent for the formulation of biological agents into a product as well as a vegetable pesticide that can be applied in the protection of plant health.

So far, there is very little information about the I. carnea biomass extract that proves its potential as a biopesticide. In addition, studies that determine the potential for inhibition of compounds contained in this wild plant biomass against biological agents, especially Trichoderma, have not been widely carried out. This study aims to determine the chemical compounds contained in the extract of I. carnea and to determine the inhibition of crude biomass extract against $T$. asperellum in vitro.

\section{Methods}

\subsection{GCMS analysis}

The initial stage in preparing the material to be used in the analysis of the content contained in the fresh canopy biomass of I. carnea is to carry out a series of extractions. After being incubated for one week in a cupboard at $70^{\circ} \mathrm{C}$, the biomass in the form of leaves and stems that had been cut into a size of about $2.0 \mathrm{~cm}$ was crushed. The slightly refined biomass was taken as much as $20 \mathrm{~g}$ as a sample and then added $50 \mathrm{ml}$ of hexane which aims to separate the fat from the extract. The mixture is boiled for 15 minutes; after that, it is filtered. A total of $50 \mathrm{ml}$ of $70 \%$ methanol was mixed into the filtrate; after being shaken for one hour, filtering was carried out to separate the solution from allelochemical compounds. After the addition of $50 \mathrm{ml}$ of $70 \%$ methanol, then evaporation was carried out by heating at $45{ }^{\circ} \mathrm{C}$ for 30 minutes. The application of the Gas Chromatography-Mass Spectrophotometry method using QP2010 plus (Shimadzu, Japan) was applied to the resulting chemical isolates [14] to determine the composition of chemical compounds.

\subsection{In vitro inhibitory test}

Fresh canopy biomass of I. carnea was all parts of the plant except the roots, cut into small pieces measuring $2 \mathrm{~cm}$ and weighing 250 grams. Furthermore, the biomass was extracted in a $1000 \mathrm{ml}$ capacity cruiser to produce $200 \mathrm{ml}$ of fresh extract. Furthermore, the crude extract was filtered and placed in a petri dish until it reached a third of the height of the cup or about $3 \mathrm{~mm}$ from the bottom of the cup. The petri dish containing the crude extract was placed in an incubator room under ultraviolet light and incubated for six hours to kill the microbial contaminants in the crude extract. Then, $10 \mathrm{ml}$ of crude shellfish extract was taken aseptically using a sterile syringe and the tip of the needle was inserted through the 
aluminum foil cover of the glass beaker containing PDA-c at a temperature of around $450 \mathrm{c}$ and $40 \mathrm{ml}$ was still liquid. The glass beaker of a mixture of liquid PDA-c and the crude extract was shaken for three minutes until evenly distributed, then $10 \mathrm{ml}$ each was poured into petri dishes. Meanwhile, $10 \mathrm{ml}$ of liquid PDA-c without extract was also poured into a petri dish as a control. The growing media with a concentration of $2 \%$ extract was then incubated for 24 hours. In the same way, $20 \%$ extract concentration was made. The determination of two kinds of extract concentrations of $2.0 \%$ (low concentration) and 20\% (concentrated) was based on an approach to determine the response of Trichoderma to extracts under two different conditions. The first condition is a low concentration $(2 \%)$ which is an approach if the $I$. carnea extract at that concentration is sprayed onto the canopy surface where Trichoderma propagules have or will be deposited on the plant leaf surface, while at high concentrations, where I. carnea biomass is used as a carrier. and inert agent biofertilizer and/or biopesticide with active ingredient Trichoderma. After the incubation period, the next step was to inoculate the $T$. asperellum fungi which were sampled from cultures with an incubation period of 10 days. Inoculum samples with a diameter of $5.0 \mathrm{~mm}$ were placed in the middle of PDA-c media both containing and not containing extracts (Figure 1). Furthermore, the growth of the radius of the colony was observed. Replication was carried out three times with the incubation period ending at the end of a multiple of 24 hours when the growth of the control colony radius had reached $>$ $4.0 \mathrm{~cm}$ or the colony diameter almost filled the petri dish.
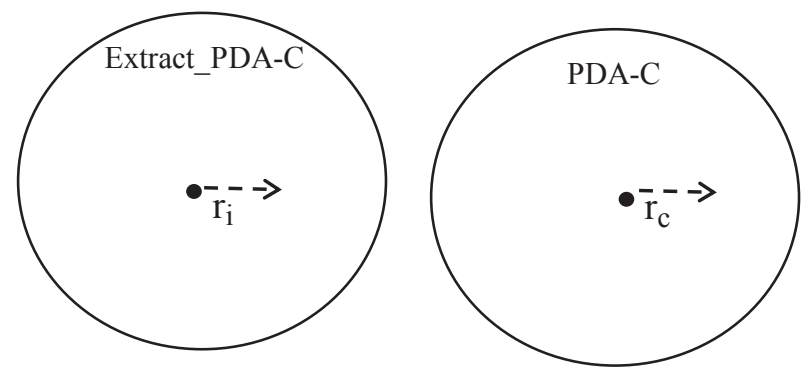

Fig. 1. In vitro test diagram of the inhibition of crude extract of I. carnea biomass against Trichoderma isolates

The inhibitory power of the extract on the growth of fungal colonies was calculated using the formula:

$$
\mathrm{IC}=\left(\mathrm{r}_{\mathrm{c}}-\mathrm{r}_{\mathrm{i}}\right) \cdot \mathrm{r}_{\mathrm{c}}^{-1} \cdot 100 \%
$$

With the following conditions: IC is the inhibitory power, rc is the radius of colony growth on PDA-c media without I. carnea extract, ri is the radius of colony growth on PDA-c media with $I$. carnea extract.

\section{Results and discussion}

\subsection{GCMS analysis}

The results of the identification of the $I$. carnea biomass extract with methanol as solvent using GCMS are presented in Table 1. 
Table 1. Result of GCMS analysis of I. carnea biomass extract with methanol as solvent

\begin{tabular}{|c|c|c|c|c|c|}
\hline $\begin{array}{l}\text { Retention } \\
\text { time } \\
\text { (mins) }\end{array}$ & $\begin{array}{c}\text { Area } \\
(\%)\end{array}$ & Compound name & Ref. & CAS No. & $\begin{array}{l}\text { Quality/ } \\
\text { Probability } \\
\text { (\%) }\end{array}$ \\
\hline 2.558 & 0.52 & 2-propanol, 1-amino- & 1933 & $000078-96-6$ & 42 \\
\hline 2.949 & 1.16 & N-PENTANAL & 3492 & $000110-62-3$ & 38 \\
\hline 3.335 & 0.89 & Propanamine & 612 & $000075-31-0$ & 47 \\
\hline 4.155 & 1.59 & Propanal, dimethylhydrazone & 6580 & 007422-93-7 & 38 \\
\hline 4.552 & 1.42 & 3-hidroxy-2methyl-4-pyrone & 17540 & $000118-71-8$ & 53 \\
\hline 6.096 & 0.41 & Propanal dimethylhydrazone & 6580 & 007522-93-7 & 50 \\
\hline 6.434 & 43.68 & Propanoic acid, propyle ester & 13052 & 000106-36-5 & 37 \\
\hline 7.164 & 1.81 & Glycinamide hydrochloride & 1663 & $001668-10-6$ & 46 \\
\hline 7.508 & 0.22 & Benzenepropanamine & 184848 & 054910-89-3 & 50 \\
\hline 7.926 & 0.27 & 5-Nitrouracil & 42913 & 000611-0805 & 47 \\
\hline 8.672 & 0.65 & Caryophyllene & 58633 & $000087-44-5$ & 99 \\
\hline 9.565 & 7.45 & 3-Piperidinol, 1-acetyl-6-methyl- & 43108 & 054751-96-1 & 38 \\
\hline 9.835 & 12.32 & 1-Butamine, N-butyl-N-methyl- & 30408 & $003405-45-6$ & 50 \\
\hline 10.094 & 6.71 & Propanal, dimethylhidrazone & 6580 & 007422-93-7 & 47 \\
\hline 10.729 & 1.91 & 2-(pentylamino) etanol & 21460 & $035161-67-2$ & 47 \\
\hline 11.348 & 0.81 & Propyl-1-D1 octyl ether & 57714 & 029739-40-6 & 43 \\
\hline 11.512 & 1.55 & p-Methoxyamphetamine & 50118 & 023239-32-9 & 35 \\
\hline 11.882 & 0.53 & $\begin{array}{l}\text { 1,2-Propanediamine, (N(1)-(2- } \\
\text { aminopropyl)- }\end{array}$ & 21439 & $007356-00-5$ & 35 \\
\hline 12.881 & 1.87 & $\begin{array}{l}\text { 2(4)-Benzofuranone, 5,6,7, 7a- } \\
\text { tetrahydro-6-hydroxy-4,4,7a- } \\
\text { trimethyl-(6S-cis)- }\end{array}$ & 80472 & 005989-02-6 & 95 \\
\hline 13.638 & 0.27 & $\begin{array}{l}\text { 1,4-Dioxaspiro[4,5]decane, } 8 \text { - } \\
\text { (methylitio) }\end{array}$ & 72199 & $055103-51-0$ & 50 \\
\hline 14.886 & 0.61 & $\begin{array}{l}\text { Iron, tricarbon yl }[(2,3,4,5-, \text { eca. })- \\
2,3,4,5 \text {-tetrahy droxy-2,4- } \\
\text { cyclopentadien-1-one }]\end{array}$ & 164566 & $117696-75-0$ & 52 \\
\hline 15.563 & 1.95 & Hexadecanonic acid & 141013 & $000057-10-3$ & 94 \\
\hline 19.455 & 10.33 & Neophytadiene & 160635 & 000504-96-1 & 78 \\
\hline 20.307 & 1.06 & $\begin{array}{l}\text { 9E)-2-(Carbomethoxy)-3-[€-3- } \\
\text { hydroxyoct-1-en-1- } \\
\text { yl]cyclopentanone }\end{array}$ & 151412 & 080009-24-1 & 50 \\
\hline & 99.99 & & & & \\
\hline
\end{tabular}

Of the 24 kinds of chemical compounds detected, three compounds were obtained whose similarity level was between $90-99 \%$ but with their respective retention times and area: (i) Caryophyllene, 8,672 minutes and $0.67 \%$, (ii) $2(4 \mathrm{H})$-Benzofuranone, 5,6,7,7atetrahydro-6-hydroxy-4,4,7a-trimethyl-,(6S-cis)-, 12,881 minutes and 1.87\%; and (iii) Hexadecanoic acid with a retention time of 15,563 minutes and $1.95 \%$. These three kinds of compounds have significant biological effects. Several caryophyllene analogs have been found with various biological functions including cytotoxic characteristics and antimicrobial activity [15], and are more effective against gram-positive bacteria than gram-negative bacteria [16]. (4H)-Benzofuranone, 5,6,7,7a-tetrahydro-6-hydroxy-4,4,7atrimethyl-, (6S-cis)- known as loliolide [17] is an identical compound with the allelochemical 2,4 -dihydroxy-7-methoxy-1,4-benzoxazine-3-one (DIMBOA) which acts as an allelopathic which can inhibit the growth of root cells [18]; This compound is a potent antioxidant isolated from Sargassum horneri which has a positive effect on cell growth [19]. Hexadecanoic acid-like compounds produced by Lactobacillus parafarraginis ZH1 
have new anti-fungal properties and have been tested for their inhibitory effects against Candida krusei 1045 and food spoilage fungus (Pichia membranefaciens 661) [20].

\subsection{In vitro inhibitory test}

The percentages of inhibition of three Trichoderma isolates grown on media containing $I$. carnea extract concentrations of $2 \%$ and $20 \%$ are shown in Figures 2 and 3, respectively.

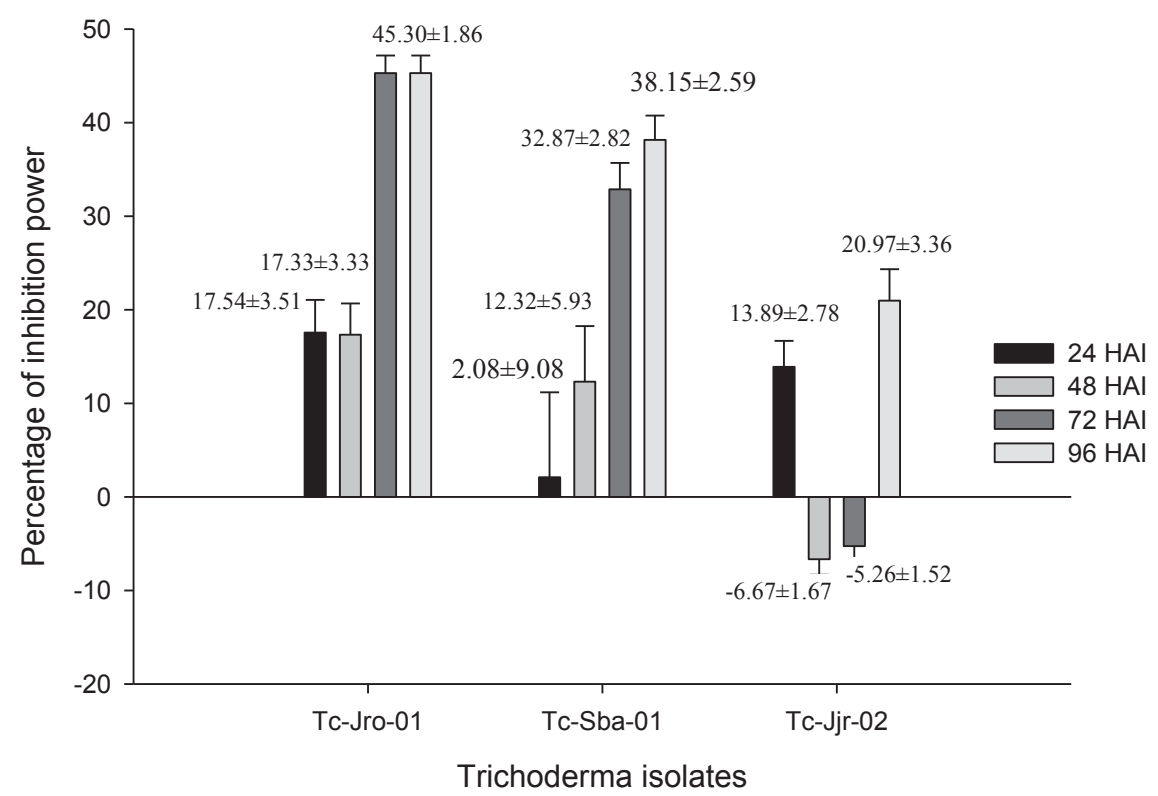

Fig. 2. Inhibition of crude extract of $I$. carnea concentration of $2 \%$ against three kinds of isolates of T. esperellum. HAI: hours after inoculation

At a concentration of $2 \%$ extract in the growing media, it appears that the inhibition of the three isolates from 24-96 HAI showed a different pattern. During the incubation period of isolate Tc-Jro-01 the percentage of inhibition at $24-48$ was 17.54 and $17.53 \%$ and increased sharply to $45 \%$ at $72 \mathrm{HAI}$ and did not change until the end of the observation. In isolate Tc-Sba-01, inhibition started at $12.32 \%$ at $48 \mathrm{HAI}$ and then increased to 32.87 $38.15 \%$ at 72 and 96 HAI. Meanwhile, the inhibition of the isolate Tc-Jjr-02 occurred at the beginning of the observation (24 HAI) and the end of the observation (96 HAI), namely 13.89 and $20.97 \%$, respectively.

The results of the inhibition test shown in Figures 2 and 3 show that there was a significant effect of Caryophyllene and Hexadecanoic acid compounds, especially on the growth of hyphae isolate cells Tc-Jro-01 and Tc-Sba-01 which occurred from 24 to 48 MSI. -caryophyllene is a bioactive terpene that has been shown to inhibit a broad spectrum of microbes [21], in certain concentrations the oxidation of -caryophyllene can be cytotoxic [22]. In the test application of extracts with low concentrations (Figure 2), it appears that the isolate Tc-Jjr-02 was also inhibited at 24 and 96 HAI. At 48 and 72 HAI these isolates were in a phase where their ability to utilize various compounds available in the media was high enough to compensate for the inhibition of the growth of hyphal cells. 3-Hydroxy-2methyl-4-pyrone and other -pyrone derivatives exhibit a broad spectrum of biological activity and exhibit significant cytotoxic and antifungal activity [23-24]. Propanoic acid, 
propyl ester are volatile organic compounds that can act as fungistatic; This compound is similar to the ester derivative produced by Hanseniaspora uvarum 793 which is effective in controlling the incidence of Botrytis cinerea in fruits, being a potential alternative to chemical fungicides or acting as synthetic fungicides [25]. Evaluation of fifteen benzenepropanamine analogs showed activity that could inhibit the fungi Trichomonas vaginalis and Candida spp. [26]. Thus the existence of 3-Hydroxy-2-methyl-4-pyrone, Propanoic acid, propyl ester, Benzenepropanamine can inhibit the Trichoderma fungus tested in this experiment.

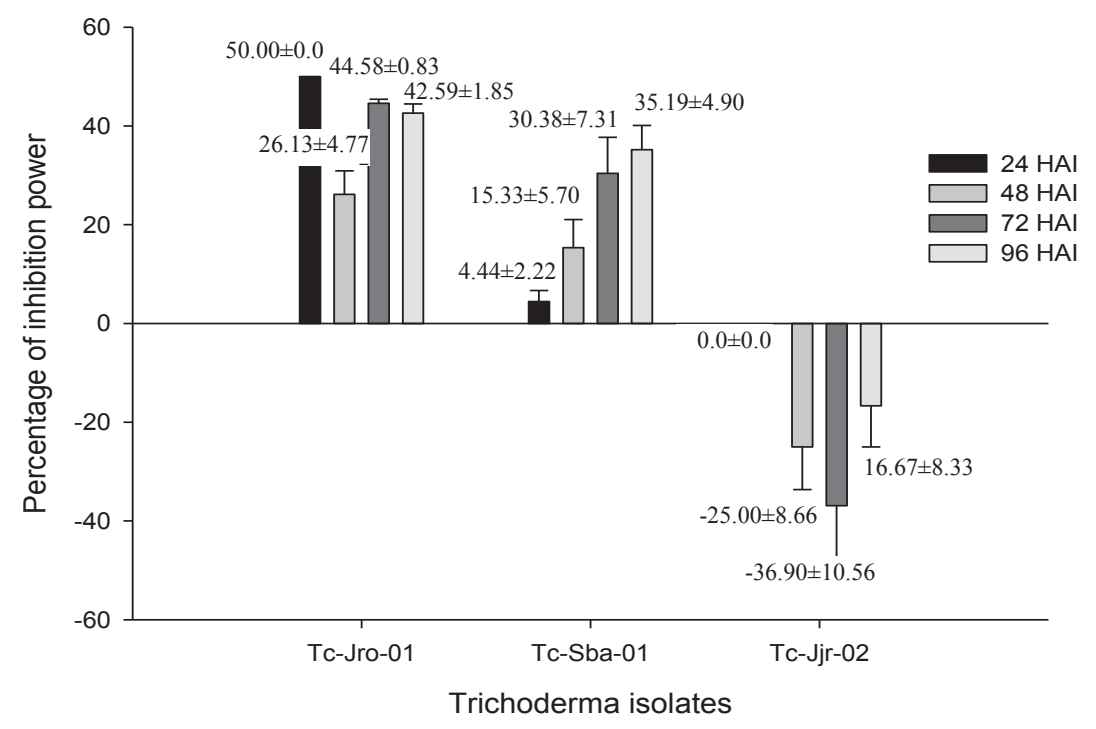

Fig. 3. Inhibition of crude extract of $I$. carnea at $20 \%$ concentration against three isolates of $T$. esperellum. HAI: hours after inoculation

The extract of I. carnea actually had the effect of inhibiting the growth of the Trichoderma isolates tested, except for the isolate Tc-Jro-02 which actually supported the growth of the colonies. At low concentrations, several compounds were effective in inhibiting the growth of hyphae. The isolate Tc-Jro-02 after 24 hours of incubation was thought to be able to utilize other compounds for biomass growth at a higher rate than inhibition by inhibitory compounds.

At high concentrations (20\%), where there will be a higher concentration of inhibitory compounds so that both isolates experience inhibition with the same pattern as at low concentrations. Meanwhile, the isolate Tc-Jjr-02 extract seemed to support the growth of hyphae. This is due to the ability of this isolate which is stronger in utilizing the various compounds available. Some Trichoderma isolates have the ability to utilize their environmental resources for nutritional sources [27-28]. However, the inhibition was higher than its ability to overcome the stress at $96 \mathrm{HAI}$.

$\mathrm{t}$ a high crude extract concentration (20\%) it appears that the isolate Tc-Jjr-02 showed its ability to utilize the resources in the media, including those contributed by several compounds contained in the I. carnea extract. Since 48 HAI the inhibitory value was negative; This indicates that the extract increased the growth of the isolate Tc-Jjr-02 colony. Oxidation of N-pentanal is an important step in metabolism and is indispensable for aerobic organisms [29] such as Trichoderma which oxidize it in order to produce energy. 
The decomposition of amino acids derived from uracil [30] will certainly be converted by Trichoderma as a component of its biomass formation.

Crude extract of I. carnea also contains various compounds that are important in metabolism for Trichoderma in addition to having potential as a biopesticide in addition to being fungistatic, namely: (i) Compound 1-Butanamine, N-butyl-N-methyl- is a volatile aromatic compound such as found in bananas [31] which can act as an attractant for fruit flies, (ii) 2-(Pentylamino)ethanol compounds have characteristics such as carbamate derivatives inhibiting cholinesterase enzymes in their toxicity to insect pests [32], (iii) pMethoxyamphetamine has potential as an active rodenticide with non-specific antiaggressive properties in male rats [33], and (iv) Neophytadiene is a compound similar to that contained in tobacco solid waste [34].

\section{Conclusions}

GCMS analysis of the Ipomea carnea biomass extract with methanol as a solvent showed the presence of 24 types of metabolites with the four highest levels consisting of Cyclopentanol (23.85\%), Piperazine (14.80\%), 4H-Pyran-4-one, 2,3 -dihydro-3,5dihydroxy-6-methyl- (11.7\%), and Benzeneethanamine, N-methyl- (10.94\%) and 3Hydroxy-2-methyl-4-pyrone, Propanoic acid, propyl ester, Benzenepropanamine which can inhibit the growth of fungal colonies. Crude extract of I. carnea at a concentration of $2 \%$ with an incubation period of 96 hours after incubation inhibited the growth of all Trichoderma esperellum isolates in vitro, namely $20.97 \pm 3.36 \%$ (Tc-Jjr-02), $38.15 \pm 32.59 \%$ (Tc-Sba-01 ), and $45.30 \pm 1.86 \%$ (Tc-Jro-01). At a concentration of $20 \%$ inhibited isolates Tc-Sba-01 and Tc-Jro-01 respectively $35.19 \pm 4.90 \%$ and $42.59 \pm 1.85 \%$, but supported the growth of isolates Tc-Jjr-02 with an inhibitory power of $-16.67 \pm 8.33 \%$. T. esperellum isolate Tc-Jjr-02 has the potential to be formulated as a fertilizer with a carrier material containing I. carnea biomass with an extract content of $20 \%$.

Acknowledgements. The authors would like to thank the Directorate General of Higher Education of the Ministry of Education, Culture, Research, and Technology of the Republic of Indonesia who has provided financial support for this research through the 2021 Higher Education Excellence Basic Research Grant.

\section{References}

1. S. Zhou, Q. Tong, X. Pan, M. Cao, H. Wang, J. Gao, and X. Ou. Energy Economics 95105137 (2021).

2. C.A.T. Gava and J.M Pinto. 2016. Biol. Control. 97: 13-20 (2016)

3. A. Chechi, J. Stahlecker, M.E. Dowling, and G. Schnabel. Pesticide Biochemistry and Physiology. https://doi.org/10.1016/j.pestbp.2019.04.002. (2019)

4. J. You, J. Zhang, M. Wu, L.Yang, W. Chen, and G. Li, G. Biological Control, 101, 31-38 (2016).

5. M.F.A. Jallow, D.G. Awadh, M.S. Albaho, V.Y. Devi, and B.M Thomas. Int. J. Environ. Res. Public Health. 14 (4): 340 (2017)

6. S. Arifin, M. Ilham, and Sutarman. J. Phys.: Conf. Ser. 1232012045 (2019)

7. A. Wachid and Sutarman. J. Phys.: Conf. Ser. 1232012020 (2019)

8. Sutarman, A. Miftahurrohmat, I.R. Nurmalasaria, and A.E. Prihatinnigrum. J. Phys.: Conf. Ser. 1764012026 (2021) 
9. Sutarman. Journal Of Agricultural Science. 139-150 (2019)

10. Sutarman, A.K. Jalaluddin, A.S. Li'aini, and A.E. Prihatiningrum. J. HPT Tropika 21(1): 18-19 (2021)

11. P.K. Saxena, D. Nanda, R. Gupta, N. Kumar, and N. Tyagi. Int. Res. J. Pharm. 8(6):1-8 (2017)

12. D. Srivastava and K. Shukla. D.D.U. Gorakhpur University, Gorakhpur, India. 7 (1): 225-235 (2015)

13. R.K. Das and A. Devkota. Studies in fungi 3(1): 293-302 (2018)

14. O.C. Ogidi, V.O. Oyetayo, and B.J. Akinyele. International Journal of Microbiology. $1-7(2015)$

15. G. Long-Fang, L. Gao-Ran, and L. Ling. Chinese Journal of Natural Medicines, 18(4), 261-267 (2020).

16. Y. Hyun-Jun; and J. Su-Kyung. Archives of Oral Biology, 88, 42-46 (2018)

17. Pubchem. https://pubchem.ncbi.nlm.nih.gov/ retrieved 6 June 2021 (2021)

18. X. Yang, Y. He, X. Song, X. Yuan, Y. Li, and D. Sun. Plant and Soil. doi:10.1007/s11104-020-04439-x (2020)

19. H.S. Kim, L. Wang, I. Fernando, P.S. Je, JG. Ko, SC. Kang, and D.S Lee. Journal of Applied Phycology.doi:10.1007/s10811-020-02154-9 (2020)

20. L. Qinhua, Y. Guoli, and J. Zhang. Biological Control, (), 104318.doi:10.1016/j.biocontrol.2020.104318 (2020)

21. N. Alsaud, K. Shahbaz, and M. Farid. Chemical Engineering Research and Design. doi:10.1016/j.cherd.2020.11.028 (2020)

22. J. Nararak, C.D. Giorgio, C. Sukkanon, V. Mahiou-Leddet, E. Ollivier, S. Manguin, and T. Chareonviriyaphap. Acta Tropica, (), 105556-(2020)

23. W. Zhang, J. Wang, H. Tang, L. Su, Y.L. Chou, S. Keryea, J. Li, C.L. Zhuang, Y.P. Luo and C.C. Xu. Chem. Biodivers. 15, 1800358-1800365 (2018)

24. Q. Zhang, W. Ma, Q. Zhao, Y. Zhao, Z. Huang, Y. Xu, D. Zhu, J. Li, and X. Zhang. Biochemical Systematics and Ecology 94104198 (2021)

25. M. Zhang, Z.H. Wang, Y.F. Mao, Y.L. Hu, L. Yang, Y.Y. Wang, L.L. Zhang, and X. Shen, Xiang. Scientia Horticulturae, 256, 108628 (2019)

26. S.T.V.S.K. Kumar; L.S. V.L. Sharma, M. Kumar, P.K. Shukla, P. Tiwari, R.K. Jain, J.P. Maikhuri, D. Singh, G. Gupta, and M.M. Singh. Bioorganic \& Medicinal Chemistry 14(19), 6593-6600 (2006).

27. F. Zhang, H. Ge, F. Zhang, N. Guo, Y. Wang, L. Chen, X. Ji X, and C. Li.. Plant Physiology and Biochemistry 100 64-74 (2016)

28. M. Li, G. Ma, H. Lian, X. Su, Y. Tian, W. Huang, J. Mei, and X. Jiang. Journal of Integrative Agriculture, 18(3), 607-617 (2019)

29. J. Li, Y. Shi, X. Fu, Y. Shu, J. Huang, J. Zhu, G. Tian, and J. Hu. Journal of Rare Earths. doi:10.1016/j.jre.2020.11.011 (2020)

30. D. Kattan, M.A. Palafox, S.K. Rathor, and V.K. Rastogi. Journal of Molecular Structure, 1106(), 300-315 (2016)

31. W. Jaleel, R. Saeed, M.Z. Shabbir, R. Azad, S. Ali, M.U. Sial, D.M. Aljedani, H.A. Ghramh, K.A. Khan, D. Wang, and Y. He. Journal of King Saud University - Science. 33101455 (2021) 
32. J. Wu, M. Pistolozzi, S. Liu, and W. Tan. Bioorganic \& Medicinal Chemistry, 115324 (2020)

33. M. Martín-López, M. Mercedes, T. Ana, M. Cavas, and J.F. Navarro. Pharmacology Biochemistry and Behavior, 167(), 9-16 (2018)

34. B. Marija, G. Tanja, C. Maja, K. Željko, S. Mojca, J. Igor, and J. Stela. Chemical Engineering Research and Design 169, 103-115 (2021). 